\title{
ANALISIS FINANSIAL PEMANENAN KAYU TEKNIK REDUCED IMPACT LOGGING MELALUI SKEMA REDD+, KALIMANTAN UTARA
}

\author{
Muhdi $^{1 *}$, Elias ${ }^{2}$, Juang Rata Matangaran² \\ ${ }^{1}$ Program Studi Kehutanan Fakultas Kehutanan USU - 20155 \\ ${ }^{2}$ Departemen Manajemen Hutan, Fakultas Kehutanan IPB, Bogor - 16680 \\ *Corresponding author : muhdisyehamad@yahoo.com
}

\section{ABSTRACT}

The research was done at natural tropical forest of PT Inhutani II, East Kalimantan. The objectives of the research were to study the carbon $(C)$ stock in the natural tropical forest after conventional and reduced impact logging (RIL) and to get the effectivity of RIL based on carbon stock, financial and environmental aspects. The effect of conventional and RIL to environment and carbon stock in the plots were studied using the data of three plots with each size $100 \mathrm{~m} \times 100 \mathrm{~m}$. The plots are placed based on purposive sampling at landing, main skiddtrail and branch skiddtrail, respectively. $C$ stocks are counted by allometric equation and $C$ economics by the economic acceptance of REDD. Economic value of RIL was IDR 1,604,518,900,- $\mathrm{ha}^{-1}$. Based on financial analysis showed that RIL was feasible and profitable at rate of interesst $16 \%$.

Key Word : RIL, carbon, finansial analysis, tropical natural forest, east Kalimantan

\section{PENDAHULUAN}

Peningkatan konsentrasi $\mathrm{CO}_{2}$ akibat aktivitas kehutanan dan pengaruhnya terhadap iklim global menyebabkan perbaikan pengelolaan hutan dalam mencegah emisi $\mathrm{CO}_{2}$ mendapat perhatian yang sangat besar. Teknik pemanenan kayu Reduced Impact Logging (RIL) merupakan usaha perbaikan pengelolaan hutan tropis yang diharapkan memberikan kontribusi dalam mengurangi emisi $\mathrm{CO}_{2}$ di atmosfir (Putz et al. 2008a; Peńa-Claros et al. 2008; Putz et al. 2008a).

Selama ini pengelolaan hutan alam terutama pemanenan kayunya masih tidak dilakukan secara profesional, sehingga keseluruhan sistem silvikultur yang diterapkan mengalami kegagalan. Hal ini dikarenakan dalam penerapan silvikultur, belum mengintegrasikan sistem pemanenan kayu dengan sistem silvikultur. Selain itu teknik perencanaan serta pelaksanaan pemanenan kayu yang baik dan benar masih belum dipergunakan dalam pemanenan kayu di hutan alam Indonesia (Elias, 1998).

Pemanenan kayu jika tidak terkontrol dapat menyebabkan kerusakan yang tinggi pada tanah dan tegakan yang mempengaruhi struktur dan komposisi tegakan dan regenerasi hutan. Meminimalkan kerusakan akibat pemanenan kayu merupakan prasyarat untuk mencapai pengelolaan hutan lestari (Sustainable Forest Management/SFM) karena mengurangi kerusakan tanah dan tegakan dapat menjamin regenerasi dan pertumbuhan tegakan komersial (Muhdi et al., 2012;, Sist et al. 1998). Tujuan penelitian ini adalah menilai efektivitas penerapan pemanenan kayu dengan Teknik Reduced Impact Logging (RIL) melalui Skema REDD+ di areal IUPHHK PT. Inhutani II, Kalimantan Timur ditinjau dari aspek finansial.

\section{BAHAN DAN METODE}

Penelitian lapangan dilakukan di areal IUPHHK PT. INHUTANI II, Malinau, Kalimantan Utara pada bulan Oktober Desember 2010. Petak penelitian terdiri dari petak pemanenan kayu CL dan dengan teknik RIL. Petak penelitian terletak pada petak 43 dan 45 areal IUPHHK PT. INHUTANI II yang dibuat tahun 2000-2001 yang memiliki keadaan topografi dan tegakan yang relatif sama, dimana masing-masing blok berukuran 100 ha. 
Pemanenan kayu CL dilakukan pada petak 43 dan teknik RIL pada petak 45 .

Pada masing-masing petak pemanenan kayu didalamnya dibuat 3 (tiga) petak contoh permanen (PCP) dengan ukuran masingmasing $100 \mathrm{~m} \mathrm{x} 100 \mathrm{~m}$ (1 ha). Masing-masing PCP ini dibagi menjadi 25 sub petak dengan ukuran $20 \mathrm{~m}$ x $20 \mathrm{~m}$.

Untuk melakukan analisis finansial pemanenan kayu, seluruh penerimaan dan pengeluaran pemanenan kayu CL dan dengan teknik RIL disusun dalam aliran kas/uang/cash flow yang mengambarkan aliran kas masuk (in flow) dan aliran kas keluar (out flow) (Lidiawati 2002, Healy et. al 2000). Aliran kas masuk/pendapatan dan aliran kas keluar/pengeluaran tersebut disusun dalam tabel aliran kas. Apabila telah disusun arus kas setiap tahun selama umur kegiatan maka selanjutnya dihitung nilai sekarang (present value) dengan menggunakan discount factor (DF).

\section{HASIL DAN PEMBAHASAN}

\section{Massa Karbon Hutan pada Areal yang Dipanen dengan Teknik RIL dan Konvensional}

Penyerapan karbon didefinisikan sebagai produktifitas bersih karbon tahunan
(tC/ha/th) dikalikan dengan separuh umur (th) karbon yang terikat dalam hutan, yang menghasilkan dimensi penyerapan t $\mathrm{C}$ per ha. Massa karbon dalam hutan adalah rata-rata jumlah karbon yang terdapat pada lahan selama siklus hidup vegetasi hutan, atau massa karbon rata-rata per satuan waktu.

Untuk menduga kemungkinan peningkatan stok karbon, maka diperlukan model pertumbuhan tegakan yang dapat menduga nilai stok karbon tersebut pada masa yang akan datang. Model pertumbuhan tegakan yang dipergunakan untuk menghitung pertumbuhan massa karbon vegetasi hutan adalah model dinamika struktur tegakan (DST). Data yang dipergunakan untuk penghitungan tersebut diperoleh dari petak 43 (konvensional) dan 45 (RIL) pada tahun 2000 (tahun ke-0) dan hasil pengukuran terakhir terhadap petak 43 dan 45 pada tahun 2010 (tahun ke-10). Untuk memperoleh massa karbon tegakan dipergunakan persamaan alometrik karbon pohon hasil penelitian ini, yaitu $C=0,017597 D^{2,73}$. Hasil perhitungan jumlah massa karbon tegakan per klas diameter berdasarkan model pertumbuhan tegakan pada hutan bekas tebangan teknik konvensional dan RIL dapat dilihat pada Tabel 1 dan Tabel 2.

Tabel 1. Perkembangan massa karbon tegakan per hektar per kelas diameter pada hutan bekas tebangan pada petak pemanenan kayu konvensional.

\begin{tabular}{ccccccc}
\hline \multirow{2}{*}{ Tahun } & \multicolumn{5}{c}{ Massa karbon per ha per kelas diameter (ton C/ha) } \\
\cline { 2 - 7 } & $\begin{array}{c}10-22,5 \\
\mathrm{~cm}\end{array}$ & $\begin{array}{c}22,5-35 \\
\mathrm{~cm}\end{array}$ & $\begin{array}{c}35-47,5 \\
\mathrm{~cm}\end{array}$ & $\begin{array}{c}47,5-60 \\
\mathrm{~cm}\end{array}$ & $\geq 60 \mathrm{~cm}$ & Jumlah \\
\hline 0 & 2,78 & 8,62 & 11,28 & 7,70 & 12,67 & 43,06 \\
10 & 3,26 & 11,25 & 13,45 & 10,86 & 22,51 & 61,32 \\
20 & 3,51 & 13,83 & 16,76 & 13,88 & 35,40 & 83,39 \\
30 & 3,63 & 15,84 & 20,75 & 17,50 & 50,50 & 108,22 \\
\hline
\end{tabular}

Pada Tabel 1 menunjukkan bahwa massa karbon tegakan bekas tebangan pada petak konvensional sebesar 43,06 ton $\mathrm{C} /$ ha pada tahun setelah pemanenan kayu kemudian meningkat pada 10 tahun setelah pemanenan menjadi 61,32 ton $\mathrm{C} / \mathrm{ha}$. Pada tahun ke-20 setelah pemanenan massa karbon tegakan menjadi 83,39 ton $\mathrm{C} / \mathrm{ha}$. Pada tahun ke-30 setelah pemanenan massa karbon tegakan menjadi sebesar 108,22 ton $\mathrm{C} / \mathrm{ha}$. Bila dibandingkan dengan massa karbon awal (sebelum penebangan) dan tahun setelah penebangan yakni masing-masing sebesar 147,81 ton $\mathrm{C} /$ ha dan 43,06 ton $\mathrm{C} /$ ha, maka terjadi penurunan massa karbon tegakan akibat pemanenan kayu konvensional sebesar 104,75 ton $\mathrm{C} /$ ha. Jadi akibat pemanenan kayu 
dengan teknik konvensional cadangan massa karbon tegakan turun sebesar $70,87 \%$ dari massa karbon sebelum pemanenan. Setelah satu siklus tebang (30 tahun) potensi massa karbon pada tegakan bekas pemanenan teknik konvensional adalah sebesar 108,22 ton $\mathrm{C} /$ ha atau 73,22 \% dari massa karbon tegakan sebelum pemanenan.

Tabel 2. Perkembangan massa karbon tegakan per hektar per kelas diameter pada hutan bekas tebangan pada petak pemanenan kayu RIL.

\begin{tabular}{ccccccc}
\hline \multirow{2}{*}{ Tahun } & \multicolumn{5}{c}{ Massa karbon per ha per kelas diameter (ton C/ha) } \\
\cline { 2 - 7 } & $\begin{array}{c}10-22,5 \\
\mathrm{~cm}\end{array}$ & $\begin{array}{c}22,5-35 \\
\mathrm{~cm}\end{array}$ & $\begin{array}{c}35-47,5 \\
\mathrm{~cm}\end{array}$ & $\begin{array}{c}47,5-60 \\
\mathrm{~cm}\end{array}$ & $\geq 60 \mathrm{~cm}$ & Jumlah \\
\hline 0 & 4,17 & 13,02 & 13,60 & 9,51 & 21,12 & 61,42 \\
10 & 4,65 & 16,33 & 18,26 & 13,66 & 39,66 & 92,55 \\
20 & 4,90 & 19,17 & 23,58 & 18,74 & 64,02 & 130,41 \\
30 & 5,03 & 21,22 & 28,88 & 24,70 & 95,15 & 174,99 \\
\hline
\end{tabular}

Pada Tabel 2 menunjukkan bahwa massa karbon tegakan bekas tebangan pada petak RIL sebesar 61,42 ton C/ha pada tahun pemanenan kayu kemudian meningkat pada 10 tahun setelah penebangan menjadi 92,55 ton $\mathrm{C} /$ ha. Pada tahun ke-20 setelah penebangan massa karbon tegakan menjadi 130,41 ton $\mathrm{C} /$ ha. Pada tahun ke-30 massa karbon tegakan menjadi sebesar 174,99 ton $\mathrm{C} / \mathrm{ha}$. Bila dibandingkan dengan massa karbon awal (sebelum penebangan) dan tahun penebangan yakni masing-masing sebesar 135,87 ton $\mathrm{C} /$ ha dan 61,42 ton $\mathrm{C} /$ ha, maka terjadi penurunan massa karbon tegakan akibat pemanenan kayu dengan teknik RIL sebesar 74,45 ton $\mathrm{C} /$ ha. Jadi terjadi penurunan massa karbon tegakan akibat pemanenan dengan teknik RIL sebesar 54,79 \% dari massa karbon sebelum pemanenan. Setelah satu siklus tebang (30 tahun) massa karbon tegakan bekas pemanenan dengan teknik RIL sebesar 174,99 ton $\mathrm{C} /$ ha atau $128,79 \%$ dari massa karbon tegakan sebelum pemanenan.

Berdasarkan uraian di atas dapat disimpulkan bahwa pemanenan kayu dengan teknik RIL dapat mencapai kelestarian hasil setelah 30 tahun (satu siklus tebang), sedangkan pemanenan kayu dengan teknik konvensional baru mencapai massa karbon sebesar 73,22 \% dari massa karbon tegakan sebelum pemanenan, yang berarti belum mencapai kelestarian hasil.

\section{Analisis Finansial Implementasi Teknik RIL}

Untuk mengetahui keberhasilan penanaman modal pada pemanenan kayu dengan teknik RIL apakah akan mampu menghasilkan keuntungan pada tingkat tertentu maka dilakukan analisis kelayakan finansial. Analisis kelayakan finansial erat hubungannya dengan rasio pendapatan dan pengeluaran suatu kegiatan, sehingga hasil analisis memberikan gambaran tentang pelaksanaan kegiatan tersebut.

Perhitungan biaya dalam penelitian ini melalui pengamatan langsung dilakukan di lapangan, arsip perusahaan dan wawancara. Biaya yang dilakukan dengan pengamatan langsung di lapangan meliputi : biaya ITSP dan survai topografi, perencanaan pemanenan kayu, penandaan jalan sarad, TPn, arah rebah pohon dan pemotongan liana, pembukaan dan konstruksi jalan sarad, penebangan, penyaradan, rehabilitasi kerusakan setelah penebangan, inspeksi blok dan perbaikan kerusakan kerusakan tegakan tinggal. Adapun biaya yang diperoleh dari arsip perusahaan merupakan biaya yang diasumsikan sama antara teknik pemanenan kayu konvensional dan RIL.

Untuk melakukan analisis finansial selain dasar-dasar perhitungan yang telah diuraikan di atas, digunakan asumsi-asumsi sebagai berikut :

1. Tingkat suku bunga umum diasumsikan yang berlaku saat ini yaitu sebesar $16 \%$ 
dan tingkat inflasi $10 \%$. Untuk keperluan analisis tingkat suku bunga yang dipergunakan adalah $16 \%$ dan $18 \%$.

2. Selama jangka analisis diasumsikan tidak terdapat perubahan kebijaksanaan yang mendasar menyangkut pengusahaan hutan, sehingga tidak terjadi perubahan yang mempunyai konsekuensi biaya cukup besar.

3. Untuk menyederhanakan perhitungan, maka diasumsikan biaya-biaya yang dianggap sama pada pemanenan kayu konvensional dan RIL tidak diperhitungkan. Yang akan diperhitungkan dalam analisis finansial ini adalah perbedaan/selisih pendapatan dan pembiayaan antara pemanenan kayu konvensional dan RIL.

Besarnya jumlah biaya yang dikeluarkan pada pemanenan kayu konvensional dan teknik RIL sebesar $\mathrm{Rp}$ 296.000,00,-/ $/ \mathrm{m}^{3}$ dan Rp $313.803,13,-/ \mathrm{m}^{3}$. Peningkatan biaya pemanenan teknik RIL dibandingkan dengan pemanenan kayu konvensional yang harus dikeluarkan setiap tahunnya adalah sebesar Rp. 358.256.110,00,-
- Tambahan biaya ini adalah karena adanya kegiatan yang berbeda antara pemanenan kayu dengan teknik konvensional dan RIL, yaitu pengeluaran untuk kegiatan ITSP dan survai topografi, perencanaan operasional pemanenan kayu, penandaan jalan sarad, penandaan TPn, penandaan arah rebah, pemotongan liana, pembukaan dan konstruksi jalan sarad, penebangan, penyaradan, rehabilitasi kerusakan setelah pemanenan dan inspeksi blok.

Peningkatan pendapatan pemanenan kayu RIL dibandingkan dengan pemanenan kayu konvensional setiap tahunnya adalah sebesar Rp 976.030.570,-. Tambahan pendapatan pada pemanenan dengan teknik RIL ini dikarenakan adanya peningkatan dalam pemanfaatan kayu dan berkurangnya biaya perbaikan kerusakan. Dengan demikian peningkatan kas bersih/keuntungan pemanenan kayu dengan teknik RIL dibandingkan dengan pemanenan kayu konvensional setiap tahunnya sebesar Rp 617.774.460,--

Tabel 3. Rekapitulasi hasil analisis finansial pemanenan kayu dengan teknik RIL.

\begin{tabular}{cllr}
\hline No. & Indikator investasi & Satuan & \multicolumn{1}{c}{ Nilai } \\
\hline 1. & Total Biaya & $\mathrm{Rp}$ & 7.871 .406 .490 \\
2. & Total Penerimaan & $\mathrm{Rp}$ & 10.866 .691 .750 \\
3. & NPV & $\mathrm{Rp}$ & 1.604 .518 .900 \\
4. & NPV/ha & $\mathrm{Rp} / \mathrm{ha}$ & 2.517 .290 \\
5. & BCR & - & 2,01 \\
6. & IRR & $\%$ & 34,31 \\
\hline
\end{tabular}

Dari hasil analisis finansial seperti pada Tabel 3 dapat diketahui bahwa pada tingkat suku bunga $16 \%$ antara kegiatan pemanenan kayu teknik RIL dibandingkan dengan teknik konvensional, memberikan tambahan keuntungan (net present value/NPV) positif sebesar $\mathrm{Rp}$ 2.517.290/ha dengan rasio pendapatan pembiayaan (benefit cost ratio/BCR) lebih besar dari satu yaitu 2,01 dan nilai internal rate of return (IRR) sebesar $34,31 \%$. Berdasarkan analisis tersebut di atas maka dapat disimpulkan bahwa kegiatan pemanenan kayu dengan teknik RIL menurut kriteria analisis finansial adalah layak untuk dilaksanakan.

Bila dibandingkan dengan penelitian Holmes et al. (1999) di Amazon, Brasil menunjukkan bahwa penerapan teknik RIL menurunkan biaya total sebesar $5 \%$ bila dibandingkan dengan biaya pemanenan kayu konvensional dimana teknik RIL menurunkan biaya penyaradan sebesar $41 \%$ walaupun dan biaya penebangan lebih tinggi dibandingkan dengan pemanenan kayu konvensional. Boltz et al. (2003) menyatakan bahwa dari aspek analisis finansial pemanenan kayu teknik RIL lebih baik dibandingkan dengan pemanenan 
kayu konvensional apabila limbah pemanenan kayu diperhitungkan.

Penerapan teknik RIL merupakan salah satu bagian dari pengelolaan hutan lestari yang berkaitan erat sebagai opportunity cost terhadap prasyarat silvikultur yang diperlukan dalam memelihara produktivitas dan ekosistem hutan. Hasil penelitian di Kongo dan Kamerun yang dilakukan de Blas dan Perez (2008) menyatakan bahwa pemanenan kayu teknik RIL akan diterima oleh para pengusaha jika benar-benar mendapatkan manfaat dari pasar melalui skema sertifikasi dan lebih mengikat.

Berkenaan dengan perkembangan mekanisme REDD, pengelolaan hutan alam dengan pemanenan kayu teknik RIL dapat berpartisipasi dalam mekanisme tersebut sepanjang syarat dan ketentuan dapat dipenuhi. Salah satu syarat teknis adalah terjadinya peningkatan kapasitas serapan karbon melalui perubahan pengelolaan hutan dengan sistem TPTI yang menggunakan pemanenan kayu konvensional menjadi RIL, yang secara kesatuan lanskap tertentu dapat berkontribusi menurunkan emisi $\mathrm{CO}_{2}$ dan meningkatkan penyerapan $\mathrm{CO}_{2}$ dari atmosfir. Berdasarkan hasil pengukuran biomassa dan massa karbon di lokasi penelitian menunjukkan bahwa teknik pemanenan kayu RIL memenuhi syarat mengurangi kehiolangan massa karbon dalam tegakan hutan dibandingkan dengan pemanenan kayu konvensional.

\section{SIMPULAN}

Berdasarkan analisis finansial pemanenan kayu teknik RIL menguntungkan dan layak diusahakan pada tingkat suku bunga $16 \%$.

\section{DAFTAR PUSTAKA}

Boltz F, Holmes TP, Carter DR. 2003. Economic and environmental impacts of conventional and reduced-impact logging in tropical south America: a comparative review. Forest Policy and Economics 5: 69-81

De Blas DE, Perez MR. 2008. Prospects for reduced impact logging in Central African logging concessions. Forest
Ecology and Management 256 15091516.

Elias. 1998. Reduced Impact Wood Harvesting in Tropical Natural Forest in Indonesia : Forest-Case Study 11. Rome: Food and Agriculture Organization of the United Nation.

Healy JR, Price C, Tay J. 2000. The cost of carbon retention by reduced impact logging. Forest Ecology and Management 126:237-255.

Holmes TP, Blate GM, Zweede JC, Pereira JR, Barreto PF, Boltz FR. 1999. Financial costs and benefits of reduced impact logging telative to conventional logging in eastern Amazon. New Clorado : USDA Forest Sevice.

Lidiawati I. 2002. Analisis finansial pemanenan kayu dengan teknik reduced impact timber harvesting [Tesis]. Sekolah pascasarjana, Institut Pertanian Bogor.

Muhdi, Elias, Daniel Murdiyarso, Juang R. Matangaran. 2012. Kerusakan tegakan tinggal akibat pemanenan kayu Reduced Impact Logging dan konvensional di hutan alam tropika, Kalimantan Timur. Jurnal Manusia dan Lingkungan Vol. 19(3):303-311/2012.

Peńa-Claros M, Fredericksen TS, Alarcon A, Blate GM, Choque U, Leano C, Licona JC, Mostacedo B, Pariona W, Villegas Z, Putz FE. 2008. Beyond reduced impact logging: silvicultural treatments to increase growth rates of tropical trees. Forest Ecology and Management 256:1458-1467.

Putz FE, Sist P, Fredericksen T, Dykstra D. 2008a. Reduced impact logging : challenges and opportunities. Forest Ecology and Management 256: 14271433.

Putz FE, Zuidema PA, Pinard MA, Boot RGA, Sayer JA, Rene G. A. Boot, Plinio Sist, Elias, Jerome K. Vanclay. 2008b. Improved tropical forest management for carbon retention. PLoS Biol 6(7):e166 doi:10.1371/journal.pbio.0060166.

Sist P, Sheil D, Kartawinata K, Priyadi H. 2003. Reduced impact logging in 
Indonesian Borneo: some results confirming the need for new silvicultural prescription. Forest Ecology and Management 179:415-427.

Van der Hout P. 2000. Testing the applicability of reduced impact logging in greenheart forest in Guyana. International Forestry Review 2(1): 2432. 